\title{
Examination of the factor structure of critical thinking disposition scale according to different variables
}

\author{
Ebru Demircioğlu ${ }^{1, ~ *, ~ S e v i l a y ~ K i l m e n ~}{ }^{2}$ \\ ${ }^{1}$ Dept. of Assessment and Evaluation in Education, Çankırı Karatekin Üniversitesi, Çankırı, Turkey \\ ${ }^{2}$ Dept. of Assessment and Evaluation in Education, Abant İzzet Baysal Üniversitesi, Bolu, Turkey
}

\section{Email address:}

sevilaykilmen@yahoo.com (S. Kilmen)

\section{To cite this article:}

Ebru Demircioğlu, Sevilay Kilmen. Examination of the Factor Structure of Critical Thinking Disposition Scale According to Different Variables. American Journal of Theoretical and Applied Statistics. Special Issue: Computational Statistics.

Vol. 4, No. 2, 2015, pp. 1-8. doi: 10.11648/j.ajtas.s.2015040101.11

\begin{abstract}
The information and technology age has brought rapid changes and transformations in the education system, and focused on raising qualified individuals who can choose, organize and use information; think on a critical and creative basis in the process; conduct research; solve problems; calculate possibilities and make deductions. Critical thinking, one of the most important characteristics one should possess, is a complicated and comprehensive process in which high-level skills are used. The development of critical thinking skills is a primary target of elementary curricula, which were reconstructed within the scope of the 2004 education reform. Such programs have introduced fundamental changes in educational activities upon the adoption of the constructivist education approach rather than the traditional approach. The present study aims to examine the factor structure of the Critical Thinking Disposition Scale (EMI) according to the genders and socio-economic statuses (SES) of different groups; and to determine whether the structure applies to different groups. A survey method is used in the research. The study population comprises a total of 39049 first-grade high school students from Ankara. The districts are categorized according to the low, medium and upper-SESs of the populations, and the research sample comprises 1264 first-grade high school students chosen via random and stratified sampling methods. Data was analyzed and reported in accordance with the quantitative analysis technique. In order to determine the three-factor structure of the scale according to the genders and socio-economic statuses of the groups, Multi Group Confirmatory Factor Analysis (MGCFA) was conducted. Model A was determined to be the basis, and three alternative models are constructed. Model D, in which error variances were released, was found to have better fit values. MGCFA was conducted in the groups categorized according to low, medium and upper SES. Model A, the basic model; as a result of the paired comparisons of the models, Model E-in which factor correlation and error variances were released-was determined to have better fit indices than the others. As a result of the research, the confirmatory model is determined not to be different in terms of the factor loads and inter-factors correlation in the groups categorized according to gender, but to differ in terms of error variances. In the groups categorized according to SES, the confirmatory model does not differ in terms of factor loads, but differs in terms of error variances and factor correlations.
\end{abstract}

Keywords: Critical Thinking, Critical Thinking Disposition, Structure Validity, Multi Group Confirmatory Factor Analysis

\section{Introduction}

Critical thinking students are provided with feedback through various tools developed to evaluate cognitive theories, experimental studies, program development, program construction and critical thinking. Although many educationists and philosophers keep developing their visions, definitions and research models, critical thinking still preserves its complicated structure, as it cannot be limited by simple definitions. In 1990, 46 experts reached a consensus regarding the definition of an ideal critical thinker. According to them:

"An ideal critical thinker is always curious, intellectual, conscious, open-minded, able to change his/her own ideas, objective while making evaluations, honest against personal prejudices, cautious while making decisions, eager to think over, clear regarding the issues, systematic regarding 
complicated issues, vigorous to search for irrelevant information, plausible while choosing the criteria, focused on asking questions and insistent in examining the results according to the conditions of permission to question" (American Philosophical Association, 1990).

In the education reports of countries such as the U.S.A, England and Austria, critical thinking is considered to be the key to raising qualified students within the education process (American Association of Colleges and Universities, 2005; Australian Council for Educational Research, 2002; Higher Education Quality Council, 1996). The recent education reforms in both western countries and Asian countries such as China and Japan support the development of critical thinking in order to enable the participation of students in liberal society. In the 2005 report of the The Association of American Colleges and Universities, only 6\% of the high-level universities performed satisfactorily in teaching critical thinking. Although educational institutions include programs created to develop the critical thinking ability of students, experts stated that critical thinking education was not given on an open and systemic basis in many schools, especially those centered on traditional teachers (Paul, Elder \& Bartell, 1997). This situation results from the fact that critical thinking education includes many difficulties, one of which is the lack of an objective and efficient evaluation tool to measure whether the critical thinking of students is weak or strong (Ennis, 2003; Halpern, 2003; Norris, 2003). According to Ennis (2003), the reasons why critical thinking should be evaluated are as follows:

1. To determine the critical thinking levels of students,

2. To provide students with feedback regarding their critical thinking skills,

3. To motivate students towards critical thinking,

4. To inform teachers students' progress in critical thinking,

5. To conduct studies on teaching and learning critical thinking,

6. To help students decide whether they should participate in education programs,

7. To obtain information from schools regarding the critical thinking skills of students.

The $6^{\text {th }}$ and $7^{\text {th }}$ reasons above include "high graded" tests, because these relate more to the test results. Examples of well-regarded critical thinking tests include: The American College Test (ACT), Iowa Test of Educational Development ve Graduate Record Examination (GRE), Law School Aptitudes Test (LSAT).

In the Delphi Report (1990), Facione stated that only content validity, structure validity, reliability and objectivity should be considered when developing an assessment tool to be used in evaluating critical thinking, and explained these characteristics as follows:

Content validity: Assessment tool should be developed according to the content of critical thinking, and the evaluation purposes of critical thinking should be clearly stated.

Structure validity: Critical thinking should be evaluated in order to determine good critical thinkers. Inadequate or wrong answers result from insufficient or weak critical thinking.

Reliability: Each question should be prepared so that the good critical thinker gets better results than the weak critical thinker.

Objectivity: The backgrounds, reading abilities and life experiences of all students are considered to be equal while deciding on their critical thinking skills.

A new experimental pattern produced in order to test structure validity of measurement tool is testing the equivalence of factor structure of the scale in different groups. When the factor structures defined for measurement tool are not equal in groups, structure validity is determined through a new way since the scores that groups obtain from these structures does not have the same meaning. Equal factor structures for groups indicate the validity of scores of groups obtained from sub-scales. In line with this basic problem, this research examined the diffirantiation state of the factor structure of the scale for groups according to gender and SES variable in order to test the structure validity of "Critical Thinking Disposition (EMI)" scale.

This study aims to examine the structure validity of the scale through testing the equivalence of factor structure. Accordingly, the following questions were asked within the research:

Does the three-factor structure of EMI differ according to gender?

Does the three-factor structure of EMI differ according to the SESs of students?

\section{Method}

\subsection{Sample}

The sample of the research consists of 1264 first-grade high school students from Ankara during the 2011-2012 academic year. According to statistics obtained from the Ministry of Education, there are 39049 first grade high school students in Ankara during the 2011-2012 academic year. The sample was chosen from 125 secondary schools in eight central districts (Altındağ, Çankaya, Etimesgut, Gölbaşı, Keçiören, Mamak, Sincan and Yenimahalle) via random and stratified sampling methods. The schools in Çankaya from upper SES, Yenimahalle from medium SES and Altındağ from low-SES were taken as stratum. Distributions of the students according to gender and SES are given in Table 1.

Table 1. Distributions of the students according to gender and SES

\begin{tabular}{lllllll}
\hline \multirow{2}{*}{ District (SES) } & \multicolumn{1}{c}{ Men } & \multicolumn{3}{c}{ Women } & \multicolumn{2}{c}{ Total } \\
\cline { 2 - 7 } & f & \% & f & \% & f & \% \\
\hline Low & 196 & 15.50 & 209 & 16.54 & 405 & 32.04 \\
Medium & 216 & 17.09 & 228 & 18.04 & 444 & 35.12 \\
Upper & 203 & 16,06 & 212 & 16.77 & 415 & 32.84 \\
Total & 615 & 48.65 & 649 & 51.35 & 1264 & 100.00 \\
\hline
\end{tabular}

According to Table $1,48.65 \%$ of the students were male, 
while $51.35 \%$ were female; SESs were classified as $32.04 \%$ low, $35.12 \%$ medium and $32.84 \%$ upper.

\subsection{Data Collection Tool}

The original "Critical Thinking Disposition Assessment (EMI)" scale was developed by Ricketts and Rudd in 2005. The scale is a five-point Likert scale, consisting of 26 items. Sub-dimensions of the scale are "Engagement, Cognitive Maturity and Innovativeness". People who are disposed to engagement accept that one should always think well; and seek opportunities to use their thinking skills in reasoning, problem solving and decision making. People who are cognitively mature are aware that many problems they encounter are actually more complicated than they initially appear. People who are innovative are described being "hungry to learn". Examining the guidebook of the scale, the reliability coefficient of the sub-dimensions are $.90, .78$ and .79 , respectively. The Cronbach-alpha reliability coefficient is .93 .

The EMI scale was adapted to Turkish culture by author (2012). The validity and reliability of the scale were examined using a sample of 1264 first-grade high school students. First, the linguistic equivalence of the scale was examined. The correlation coefficients between the English and Turkish versions of the scale (re-test interval was two weeks) were $.68, .54$ and .76 for the sub-dimensions "Engagement", "Cognitive Maturity", and "Innovativeness", respectively; and was. 76 for the whole scale $(p<.01)$. Moreover, the analyses indicated that there was no significant difference between the scores obtained from the Turkish and English versions of the scale. The correlations between the scores obtained from the Turkish and English versions of the scale were significant, whereas the $t$ values were non-significant; therefore, the scale was considered to be translated appropriately, thus achieving linguistic equivalence. Structure validity was established via exploratory factor analysis, confirmatory factor analysis and criterion validity. As a result of the exploratory factor analysis, the three-factor structure of the original scale was found to be preserved in the Turkish version. The confirmatory factor analysis confirmed the three-factor model obtained via the exploratory factor analysis. The California Critical Thinking Disposition Scale (CCTDI) adapted into Turkish culture by Kökdemir (2003) was chosen as the similar criterion in order to determine the criterion validity. The analysis indicated the correlation coefficient between EMI and CCTDI to be .42, and indicated positive, medium-level and significant relationships between the two scales $(\mathrm{p}<.01)$. Reliability values of the Cronbach-alpha internal consistency and test-retest were examined in order to determine the reliability of the scale and its sub-dimensions. Internal consistency coefficients of the "Engagement", "Cognitive Maturity" and "Innovativeness" sub-dimensions were found to be .84, .71 and .87 , respectively. The internal consistency coefficient of the whole scale was determined to be .88 . The stability coefficients of the test-retest were found to be $.76, .70$ and .71 for the "Engagement", "Cognitive Maturity" and "Innovativeness" sub-dimensions, respectively. The test-retest reliability coefficient of the whole scale was found to be .78 . Considering the acceptance level to be .70 for reliability, all of the sub-dimensions and the whole scale were determined to have sufficient internal consistency.

\subsection{Procedures}

The scale sealed by Provincial Directorate for National Education were copied and applied to students having education in sample schools. The researcher implemented whole study, which was based on voluntary principle in line with research ethics.

\subsection{Data Analysis}

Data was analyzed via LISREL version 8.7 , and the significance level was considered to be .05 . The validity of the scale was examined via MGCFA in light of the purposes of the research.

\section{Findings}

This section presents and discusses the findings in relation to the research questions.

\subsection{Findings Regarding the Multi Group Confirmatory Factor Analysis}

Table 2. Standardized t and Lambda-x values of EMI scale substances

\begin{tabular}{llll}
\hline & Items & t & $\lambda$ \\
\hline & 2 & - & .72 \\
3 & 15.94 & .48 \\
Engagement & 5 & 18.17 & .55 \\
& 7 & 18.26 & .55 \\
& 8 & 17.41 & .53 \\
Innovativeness & 9 & 18.87 & .57 \\
& 14 & 18.59 & .56 \\
& 17 & 18.15 & .55 \\
& 18 & 23.79 & .73 \\
& 19 & 19.87 & .60 \\
& 22 & 16.95 & .51 \\
1 & - & .43 \\
& 13 & 10.94 & .47 \\
& 16 & 9.12 & .35 \\
& 20 & 11.14 & .49 \\
& 24 & 12.46 & .62 \\
& 25 & 11.57 & .52 \\
& 26 & 11.05 & .48 \\
& 12 & -96 \\
& 15 & 39.19 & .79 \\
& 21 & 28.49 & .66 \\
& 6 & 20.32 & .62 \\
& 10 & 48.77 & .87 \\
& 22.99 & .87 \\
& & 23.43 & .58 \\
\hline
\end{tabular}

MGCFA was conducted on the groups categorized according to gender and SES in order to obtain scientific evidence regarding the structure validity of the scale. Prior to the testing of the equivalences of the factor structures, first-order confirmatory analysis was conducted for the 
three-factor structure which was obtained as a result of the exploratory factor analysis in light of the theoretical framework of the scale. The three-factor structure obtained via the exploratory factor analysis was subjected to first-order confirmatory analysis prior to testing the equivalences of the factor structures. Following confirmatory factor analysis, the significance of the factor structure was examined at the .05 level. The relationships between the implicit (factor) and observed variables, and $\mathrm{t}$ and Lambda- $\mathrm{x}$ values of the error variances of the observed variables, are given in Table 2.

Fit indices of EMI obtained from the sample group and calculated values are given in Table 3 .

Table 3. Fit indexes of EMI's measurement model

\begin{tabular}{llllllll}
\hline$\chi^{2}$ & sd & $\mathbf{p}$ & RMSEA & AGFI & SRMR & CFI & NNFI \\
\hline 2851.35 & 272 & .00 & .08 & .82 & .06 & .91 & .90 \\
\hline
\end{tabular}

According to Table 3, confirmatory factor analysis which was conducted to examine whether the original factor structure of EMI was valid in the Turkish culture indicated the fit indices to be $\chi^{2}=2851.35(\mathrm{sd}=272, \mathrm{p}=0.00), \chi^{2} / \mathrm{sd}=$ $10.48, \mathrm{RMSEA}=.08, \mathrm{AGFI}=.82, \mathrm{SRMR}=.06, \mathrm{CFI}=.91$ and $\mathrm{NNFI}=.90$. As the proportion of the chi-square to the degree of freedom was greater than five, revisions were made between the subject matters of 18-2., 7-5. and 8-3. in light of the results of the factor analysis. Following the modifications, the relationships between the implicit (factor) and observed variables, and $t$ and Lambda- $x$ values of the error variances of the observed variables are given in Table 4 .

Table 4. Standardized t and Lambda-x values of EMI scale substances

\begin{tabular}{|c|c|c|c|}
\hline & Items & $\mathbf{t}$ & $\lambda$ \\
\hline \multirow{11}{*}{ Engagement } & 2 & _- & .62 \\
\hline & 3 & 14.34 & .48 \\
\hline & 5 & 15.13 & .51 \\
\hline & 7 & 15.13 & .51 \\
\hline & 8 & 15.52 & .53 \\
\hline & 9 & 17.08 & .59 \\
\hline & 14 & 16.65 & .58 \\
\hline & 17 & 16.42 & .57 \\
\hline & 18 & 33.30 & .63 \\
\hline & 19 & 17.42 & .61 \\
\hline & 22 & 15.85 & .54 \\
\hline \multirow{7}{*}{ Cognitive Maturity } & 1 & _- & .44 \\
\hline & 13 & 11.17 & .48 \\
\hline & 16 & 9.28 & .36 \\
\hline & 20 & 11.24 & .49 \\
\hline & 24 & 12.57 & .62 \\
\hline & 25 & 11.62 & .52 \\
\hline & 26 & 11.09 & .47 \\
\hline \multirow{7}{*}{ Innovativeness } & 4 & - & .95 \\
\hline & 6 & 39.07 & .79 \\
\hline & 10 & 28.68 & .66 \\
\hline & 12 & 20.33 & .62 \\
\hline & 15 & 48.77 & .87 \\
\hline & 21 & 23.01 & .87 \\
\hline & 23 & 23.43 & .58 \\
\hline
\end{tabular}

Post-modification fit indices of EMI obtained from the sample group and the values calculated are given in Table 5.

Table 5. Fit indexes of EMI's measurement model

\begin{tabular}{llllllll}
\hline$\chi^{2}$ & sd & $\mathbf{p}$ & RMSEA & AGFI & SRMR & CFI & NNFI \\
\hline 1240.16 & 269 & .00 & .05 & .91 & .04 & .97 & .96 \\
\hline
\end{tabular}

Post-modification results of the confirmatory factor analysis were as follows: $\chi^{2}=1240.16(\mathrm{sd}=269, \mathrm{p}=.00)$, $\chi^{2} / \mathrm{sd}=4.61, \mathrm{RMSEA}=.05, \mathrm{SRMR}=.04, \mathrm{AGFI}=.91$, $\mathrm{CFI}=.97$ and $\mathrm{NNFI}=.96$; the modifications were observed to improve the goodness of fit indices to a great extent. Comparison of the obtained values and the expected critical values confirmed the original structure of the scale.

Second, test statistics, normality tests and reliability coefficients were calculated for the sub-dimensions of each variable, gender and SES category, prior to the MGCFA, and the appropriateness of the data for MGCFA was checked. Third, confirmatory model fit indices were examined in order to determine to what extent the confirmatory model established for the levels of gender and SES variables was consistent. Finally, the equivalence of the three-factor structure of EMI was tested via MGCFA for gender and SES variables.

MGCFA was used to examine whether the assessment tool evaluates similar structures against groups. This is of particular help in determining whether the estimations of model parameters are stable against groups, or the group members are consistent with the relationships determined via confirmatory factor analysis (Kline, 2005).

\subsubsection{Does the Three-Factor Structure of the Turkish Version of EMI Differ According to Gender}

Cronbach-alpha internal consistency reliability coefficients were calculated to determine the reliabilities of male and female groups. These values are given in Table 6.

Table 6. The reliabilities of male and female groups

\begin{tabular}{lll}
\hline Gender & $\mathbf{N}$ & Cronbach- $\boldsymbol{\alpha}$ \\
\hline Women & 649 & .88 \\
Men & 615 & .89 \\
\hline
\end{tabular}

The values of the groups obtained from EMI were determined to be sufficient according to Table 7. In order to conduct a multi group analysis, first the confirmatory model should be established for the gender group, and then the established confirmatory model should produce acceptable goodness of fit indices in all the groups (male and female).

Fit indices of male and female groups calculated prior to the MGCFA for the three-factor structure of EMI are given in Table 7. 
Table 7. EMI's fit indexes of measurement model

\begin{tabular}{lllllllll}
\hline & $\chi^{2}$ & sd & $\mathbf{p}$ & RMSEA & AGFI & SRMR & CFI & NNFI \\
\hline \multirow{2}{*}{ men } & 779.19 & 269 & .00 & .05 & .89 & .05 & .97 & .96 \\
women & 789.28 & 269 & .00 & .05 & .89 & .05 & .96 & .96 \\
\hline
\end{tabular}

According to Table 7, fit indices obtained via confirmatory factor analysis of whether the data obtained from the male and female groups were consistent were $\chi^{2}=$ $779.19(\mathrm{sd}=269, \mathrm{p}=0.00), \chi^{2} / \mathrm{sd}=2.89, \mathrm{RMSEA}=.05$, $\mathrm{AGFI}=.89, \mathrm{SRMR}=.05, \mathrm{CFI}=.97$ and $\mathrm{NNFI}=.96$ for the male group; and $\chi^{2}=789.28(\mathrm{sd}=269, \mathrm{p}=0.00), \chi^{2} / \mathrm{sd}=$ 2.93, $\mathrm{RMSEA}=.05, \mathrm{AGFI}=.89, \mathrm{SRMR}=.05, \mathrm{CFI}=.96$ and $\mathrm{NNFI}=.96$ for the female group. Values of less than 3.00 in large samples indicate strong consistency (Kline, 2005; Sümer, 2000). The proportion of the chi-square value to the degree of freedom indicated that there was great consistency between the original variable matrix and the suggested matrix for male and female groups. Root mean square error of approximation (RMSEA) and standardized root mean residual (SRMR) were .05 for male and female groups. RMSEA value between .05 and .06 ( $\mathrm{Hu} \&$ Bentler, 1999; Thompson, 2004) and SRMR value between .05 and .08 (Brown, 2006; Hu \& Bentler, 1999) indicate good consistency. Goodness of fit indices (GFI) and comparative fit indices (CFI) were higher than .90. Values higher than .90 indicate good consistency.

The values obtained from the analysis indicate the acceptable level of fit indice values regarding confirmatory model within the frame of the scores of both groups from EMI. MGCFA results regarding the equivalence of the three-factor structure of EMI for male and female groups are given in Table 8 .

Table 8. MGCFA results regarding male and female groups

\begin{tabular}{|c|c|c|c|c|c|c|c|c|}
\hline Model & $\mathbf{N}$ & $\chi^{2}$ & $\chi^{2} / \mathrm{sd}$ & RMSEA & CFI & NFI & NNFI & SRMR \\
\hline$A^{1}$ & 1264 & 1677.38 & 2.82 & .054 & .96 & .95 & .96 & .06 \\
\hline $\mathrm{B}^{2}$ & 1264 & 1646.58 & 2.87 & .055 & .96 & .95 & .96 & .05 \\
\hline $\mathrm{C}^{3}$ & 1264 & 1674.17 & 2.83 & .054 & .96 & .95 & .96 & .06 \\
\hline $\mathrm{D}^{4}$ & 1264 & 1604.16 & 2.83 & .054 & .97 & .95 & .96 & .06 \\
\hline
\end{tabular}

$\mathrm{p}<.01$

${ }^{1}$ Factor loads, factor correlations and error variances were stable

${ }^{2}$ Factor loads were free (factor correlations and error variances were stable)

${ }^{3}$ Factor loads and error variances were free (factor correlations were stable)

${ }^{4}$ Error variances were free (factor loads and factor correlations were stable)

According to Table 8, Model A, which assumed that the factor structure was equal in line with the covariance matrix of male and female groups, was determined to be the basic model. Models B, C and D were established as alternatives to the basic Model A. Male and female groups in Model B, in which factor loads were set free, were found to have their own factor load values. Male and female groups in Model C, in which factor load and error variances were set free, were found to have their own factor load values, and the variables observed for both groups were found to have their own error variances. Moreover, error variances were set free in Model $\mathrm{D}$, and the variables observed for male and female groups were found to have their own error variances.

Comparing the fit indices of the models, $\chi^{2} / \mathrm{sd}$ value of Model B was observed to increase by .05 compared to Model A; however, as for all fit indices, Model B can be concluded not to have a better fit index than Model A. Examining Model $\mathrm{C}$ and Model A, an increase of .01 was observed in the proportion of chi-square value to the degree of freedom, and a significant improvement was observed in the goodness of fit indices of Model D.

Finally, the models were compared dichotomously before deciding which model was difference values, degrees of freedom and the degrees of freedom of the chi-square difference values.

Table 9. Chi-square difference values at p signifigance level and degree of freedom difference values of confirmed models for female and male groups

\begin{tabular}{llll}
\hline $\begin{array}{l}\text { Compared of } \\
\text { Model }\end{array}$ & $\begin{array}{l}\text { Difference of } \\
\text { chi-square }\end{array}$ & $\begin{array}{l}\text { Degrees of } \\
\text { Freedom }\end{array}$ & p \\
\hline A - B & 30.80 & 22 & .10 \\
A - C & 3.21 & 3 & .36 \\
A - D & 73.22 & 28 & .00 \\
\hline
\end{tabular}

$\mathrm{p}<.05$

As shown in Table 9, a significant difference was found between Model D and Model A, error variances of which were set free in all the dichotomous comparisons. The factor structure of Model D, which was established as a result of the MGCFA of the male and female groups, was examined for the significance level of .05. The relationships between the implicit (factor) and observed variables, and $\mathrm{t}$ and Lambda-x values of the error variances of the observed variables are given in Table 10. 
Table 10. Male and female groups for standardized $t$ and Lambda-x values of EMI scale substances

\begin{tabular}{|c|c|c|c|c|c|}
\hline & & Men & & Wome & \\
\hline & items & $\mathbf{t}$ & $\lambda$ & $\mathbf{t}$ & $\lambda$ \\
\hline \multirow{11}{*}{ Engagement } & 2 & - & 1.00 & - & 1.00 \\
\hline & 3 & 14.37 & .97 & $\overline{14} .37$ & .97 \\
\hline & 5 & 15.21 & .83 & 15.21 & .83 \\
\hline & 7 & 15.21 & .89 & 18.21 & .89 \\
\hline & 8 & 15.65 & .97 & 15.65 & .97 \\
\hline & 9 & 17.12 & .97 & 17.12 & .97 \\
\hline & 14 & 16.76 & .89 & 16.76 & .89 \\
\hline & 17 & 16.38 & .85 & 16.38 & .85 \\
\hline & 18 & 33.28 & 1.01 & 32.28 & 1.01 \\
\hline & 19 & 17.26 & .93 & 17.36 & .93 \\
\hline & 22 & 15.77 & .87 & 18.77 & .87 \\
\hline \multirow{7}{*}{ Cognitive Maturity } & 1 & _- & 1.00 & _ & 1.00 \\
\hline & 13 & $\overline{1} 1.08$ & 1.25 & $\overline{1} 1.08$ & 1.25 \\
\hline & 16 & 9.13 & .99 & 9.12 & .99 \\
\hline & 20 & 11.11 & 1.28 & 11.11 & 1.28 \\
\hline & 24 & 12.53 & 1.72 & 12.53 & 1.72 \\
\hline & 25 & 11.50 & 1.38 & 11.50 & 1.38 \\
\hline & 26 & 11.02 & 1.26 & 11.02 & 1.26 \\
\hline \multirow{7}{*}{ Innovativeness } & 4 & _- & 1.00 & _ & 1.00 \\
\hline & 6 & 39.24 & .86 & 19.24 & .86 \\
\hline & 10 & 28.54 & .69 & 20.54 & .69 \\
\hline & 12 & 20.65 & .56 & 20.65 & .56 \\
\hline & 15 & 48.20 & .92 & 40.90 & .92 \\
\hline & 21 & 22.01 & .54 & 22.01 & .54 \\
\hline & 23 & 22.42 & .70 & 22.42 & .70 \\
\hline
\end{tabular}

According to Table 10, the methods and factor structure of the assessment model were observed to be significant at .05 . Factor loads and error variances were also found to differ from zero. Thus, the confirmatory model in the gender group was determined not to differ in terms of factor loads and factor correlations, but to differ in terms of error variances.

\subsubsection{Does the Three-Factor Structure of EMI Differ According to Socio-Economic Status}

The Cronbach-alpha internal consistency coefficients of the reliabilities SES groups are given in Table 11.
Table 11. The reliabilities of seperated according to SES groups

\begin{tabular}{lll}
\hline SES & N & Cronbach- $\boldsymbol{\alpha}$ \\
\hline Low & 405 & .86 \\
Medium & 444 & .89 \\
Upper & 415 & .89 \\
\hline
\end{tabular}

According to Table 11, the EMI scores of the three SES groups were found to be sufficiently reliable. The confirmatory model established prior to the MGCFA should produce acceptable goodness of fit indices for the SES groups. Fit indices between the covariance matrices of the groups prior to the MGCFA are given in Table 12 .

Table 12. EMI's fit indexes of measurement model

\begin{tabular}{llllllll}
\hline & $\chi^{2}$ & sd & p & RMSEA & AGFI & SRMR & CFI \\
\hline low & 551.16 & 269 & .00 & .05 & .88 & .05 & .96 \\
medium & 633.67 & 269 & .00 & .05 & .88 & .05 & .97 \\
upper & 771.22 & 269 & .00 & .06 & .84 & .06 & .96 \\
\hline
\end{tabular}

According to Table 12, fit indices obtained via confirmatory factor analysis were: $\chi^{2}=551.16(\mathrm{sd}=269, \mathrm{p}=$ $0.00), \chi^{2} / \mathrm{sd}=2.04, \mathrm{RMSEA}=.05, \mathrm{AGFI}=.88, \mathrm{SRMR}=.05$, $\mathrm{CFI}=.96$ and $\mathrm{NNFI}=.95 ; \chi^{2}=633.67(\mathrm{sd}=269, \mathrm{p}=0.00)$, $\chi^{2} / \mathrm{sd}=2.35$, RMSEA $=.05$, AGFI $=.88, \mathrm{SRMR}=.05$, $\mathrm{CFI}=.97$ and $\mathrm{NNFI}=.96$; and $\chi^{2}=771.22(\mathrm{sd}=269, \mathrm{p}=$ $0.00), \chi^{2} / \mathrm{sd}=2.86, \mathrm{RMSEA}=.06, \mathrm{AGFI}=.84, \mathrm{SRMR}=.06$, $\mathrm{CFI}=.96$ and $\mathrm{NNFI}=.95$ for the low, medium and upper groups, respectively. Values less than 3.00 in large samples indicate a high level of consistency (Kline, 2005; Sümer,
2000). The proportion of the chi-square value to the degree of freedom indicated that strong consistency between the original variable matrix and the suggested matrix for the three SES groups.

The values obtained from the analysis indicate the acceptable level of fit indice values regarding confirmatory model within the frame of the scores of three groups from EMI. MGCFA results for the equivalence of the three-factor structure of EMI for the SES groups are given in Table 13. 
Table 13. MGCFA results regarding the low, medium and upper groups

\begin{tabular}{llllllll}
\hline \multirow{2}{*}{ MODEL } & $\chi^{2}$ & $\begin{array}{l}\chi^{2} / \mathbf{s} \\
\mathbf{d}\end{array}$ & $\begin{array}{l}\text { RMS } \\
\text { EA }\end{array}$ & CFI & NFI & $\begin{array}{l}\text { NN } \\
\text { FI }\end{array}$ & $\begin{array}{l}\text { SR } \\
\text { MR }\end{array}$ \\
\hline $\mathrm{A}^{1}$ & 2159.96 & 2.35 & .05 & .96 & .93 & .96 & .07 \\
$\mathrm{~B}^{2}$ & 2106.96 & 2.40 & .05 & .96 & .93 & .96 & .07 \\
$\mathrm{C}^{3}$ & 2142.39 & 2.34 & .05 & .96 & .93 & .96 & .06 \\
$\mathrm{D}^{4}$ & 2041.21 & 2.36 & .05 & .96 & .93 & .96 & .07 \\
\hline
\end{tabular}

$\mathrm{p}<.01$

${ }^{1}$ Factor loads, factor correlations and error variances were stable

${ }^{2}$ Factor loads were free (factor correlations and error variances were stable)

${ }^{3}$ Factor loads and error variances were free (factor correlations were stable)

${ }^{4}$ Error variances were free (factor loads and factor correlations were stable)

${ }^{5}$ Factor corrolations and error variances were free

According to Table 13, Model A, which was assumed that factor structure was equal in line with the covariance matrix of SES groups, was determined to be the basic model. Models B, C and D were established as alternatives to the basic Model A. Comparing the fit indices of the models, the $\chi^{2} /$ sd value of Model B increased by .05 compared to Model A. Evaluating this finding with other fit indices, no improvement was observed in the goodness of fit values. The $\chi^{2} / \mathrm{sd}$ value of Model $\mathrm{C}$ was decreased by .01 . No difference was found between the RMSEA, CFI, NFI and NNFI values. As no better goodness of fit index was obtained in Model C compared to Model A, Model D was examined. An increase of .01 was observed in the $\chi^{2} / \mathrm{sd}$ value of Model D compared to Model A, but no improvement was observed in other goodness of fit indices. Therefore, Model E was examined, and then MGCFA was conducted. The $\chi^{2} /$ sd value of Model E was the same as Model A. RMSEA, CFI, NFI and NNFI values remained the same. However, SRMR value decreased from .07 to .06 , thus improving the goodness of fit indices. Therefore, a significant increase was observed in the goodness of fit indices of Model $\mathrm{E}$ in which the values of factor correlations and error variances were released.

The models were compared dichotomously before deciding which model was the best. The significance levels of the models were determined according to the chi-square difference values, degrees of freedom and the degrees of freedom of the chi-square difference values (see Table 14).

Table 14. Chi-square difference values at $p$ signifigance level and degree of freedom difference values of confirmed models for low, medium and upper SES groups

\begin{tabular}{llll}
\hline $\begin{array}{l}\text { Compared of } \\
\text { Model }\end{array}$ & $\begin{array}{l}\text { Difference of } \\
\text { chi-square }\end{array}$ & $\begin{array}{l}\text { Degrees of } \\
\text { Freedom }\end{array}$ & p \\
\hline A - B & 53.00 & 44 & .16 \\
A - C & 17.57 & 6 & .00 \\
A - D & 118.75 & 56 & .00 \\
A - E & 139.81 & 62 & .00 \\
\hline
\end{tabular}

According to Table 14, Model E differed significantly from Model A. The factor structure of Model E was examined at a significance level of .05 . The relationships between the implicit (factor) and observed variables, and $t$ and Lambda-x values of the error variances of the observed variables are given in Table 15.

Table 15. Low, medium and upper groups for standardized t and Lambda-x values of EMI scale substances.

\begin{tabular}{|c|c|c|c|c|c|c|c|}
\hline & & \multicolumn{2}{|l|}{ Low } & \multicolumn{2}{|c|}{ Medium } & \multicolumn{2}{|l|}{ Upper } \\
\hline & & $\mathbf{t}$ & $\lambda$ & $\mathbf{t}$ & $\lambda$ & $\mathrm{t}$ & $\lambda$ \\
\hline \multirow{11}{*}{ Engagement } & 2 & & 1.00 & - & 1.00 & & 1.00 \\
\hline & 3 & $\overline{14} .39$ & .96 & $\overline{14} .39$ & .96 & $\overline{14} .39$ & .96 \\
\hline & 5 & 15.24 & .83 & 15.34 & .83 & 15.34 & .83 \\
\hline & 7 & 15.40 & .90 & 15.40 & .90 & 15.40 & .90 \\
\hline & 8 & 15.71 & .96 & 15.71 & .96 & 15.71 & .96 \\
\hline & 9 & 17.31 & .98 & 17.21 & .98 & 17.31 & .08 \\
\hline & 14 & 16.74 & .88 & 16.74 & .88 & 16.74 & .88 \\
\hline & 17 & 16.45 & .86 & 16.48 & .86 & 16.48 & .86 \\
\hline & 18 & 23.44 & 1.01 & 33.44 & 1.01 & 33.44 & 1.01 \\
\hline & 19 & 17.42 & .93 & 17.42 & .93 & 17.42 & .93 \\
\hline & 22 & 15.99 & .89 & 15.90 & .89 & 15.99 & .89 \\
\hline \multirow{7}{*}{ Cognitive Maturity } & 1 & _- & 1.00 & _- & 1.00 & 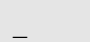 & 1.00 \\
\hline & 13 & 11.17 & 1.25 & 11.17 & 1.25 & 11.17 & 1.25 \\
\hline & 16 & 9.26 & 1.01 & 9.26 & 1.01 & 9.36 & 1.01 \\
\hline & 20 & 11.27 & 1.30 & 11.27 & 1.30 & 11.27 & 1.30 \\
\hline & 24 & 12.50 & 1.65 & 12.50 & 1.65 & 12.50 & 1.65 \\
\hline & 25 & 11.58 & 1.35 & 11.58 & 1.38 & 11.58 & 1.38 \\
\hline & 26 & 10.96 & 1.23 & 10.96 & 1.20 & 10.96 & 1.23 \\
\hline \multirow{7}{*}{ Innovativeness } & 4 & - & 1.00 & - & 1.00 & & 1.00 \\
\hline & 6 & 29.24 & .87 & 29.14 & .87 & 29.24 & .87 \\
\hline & 10 & 29.04 & .70 & 29.04 & .70 & 29.04 & .70 \\
\hline & 12 & 20.37 & .57 & 20.17 & .57 & 20.37 & .57 \\
\hline & 15 & 49.41 & .92 & 49.61 & .92 & 49.61 & .92 \\
\hline & 21 & 22.02 & .55 & 22.02 & .55 & 22.02 & .55 \\
\hline & 23 & 22.65 & .71 & 22.65 & .71 & 23.65 & .71 \\
\hline
\end{tabular}

According to Table 15, the methods and factor structure in the assessment model were significant at .05 . Factor loads and error variances were also found to differ from zero. Thus, the confirmatory model in three SES groups did not differ in terms of factor loads and factor correlations, but differed in terms of error variances. 


\section{Conclusions and Suggestions}

This research conducted a validity study on data collected from 1264 participants within the scope of the study testing the equivalence of factor structure of EMI scale. This research conducted a validity study on data collected from 1264 participants within the scope of the study testing the equivalence of factor structure of EMI scale. In order to test the equivalence of the three-factor structure of EMI in the groups formed according to gender, test statistics, the normality of the distribution and reliability coefficients were calculated for the male and female groups. The sample was found to have a normal distribution, and the reliability coefficients of both gender groups were found to be high. Confirmatory model fit indices were examined for the male and female groups. Four models were tested via MGCFA. The equivalence of the three-factor structure of EMI showed that Model D was the best in the male and female groups. The confirmatory model in the male and female groups did not differ in terms of factor loads and factor correlations, but differed in terms of error variances. The findings obtained from the research determined that three-factor structure of the scale does not differentiate according to gender.

In order to test the equivalence of the three-factor structure of EMI the low, medium and upper SES groups, test statistics, the normality of the distribution and reliability coefficients were calculated. Goodness of fit values of the confirmatory model, which were found to have a normal distribution and high reliability coefficients, were examined. When the values were determined to have good fit indices, MGCFA was conducted. Five models were used to test the equivalence of the three-factor structure of EMI the SES groups. Model E assumed that error variances and correlations were released. The confirmatory model in the SES groups did not differ in terms of factor loads, but differed in terms of error variances and factor correlations. This finding determined that three-factor structure of the scale does not differentiate according to SES. This statistical method is used to determine the validity of the measurement instrument abroad and within the country is the subject of only a few research. In order to obtain experimental evidence for the validity of the scale is very important to use this method. According to these results, EMI scale can be used in order to measure the critical thinking disposition of first grade high school students and the factor structure of the scale should be tested on different variables in order to obtain more information about its structure validity.

\section{References}

[1] American Philosophical Association. (1990). Critical thinking: A statement of expert consensus for puposes of educational assessment and instruction, In the Delphi Report: Research Findings and Recommendations Prepared for he Committee on Pre-college Philosophy.
[2] American Association of Colleges and Universities. (2005). Liberal education outcomes: A preliminary report on student achievement in college. Washington, DC: AAC\&U.

[3] Australian Council for Educational Research. (2002). Graduate skills assessment. Australia: Commonwealth of Australia.

[4] Brown, T. A. (2006). Confirmatory factor analysis for applied research (1. Edition). NY, Guilford Publications, Inc.

[5] Ennis, R. H. (2003). Critical thinking assessment. D. Fasko (Ed.), Critical thinking and reasoning (pp. 293-310), Cresskill, NJ: Hampton Press.

[6] Facione, P. A. (1990). Critical thinking: A statement of expert concensus for purposes of educational assessment and instruction. Delphi Report Executive Summary, 315-423.

[7] Halpern, D. F. (2003). Thought \& knowledge: An introduction to critical thinking (4. Edition). Mahwah, New Jersey: Lawrence Erlbaum Associates.

[8] Higher Education Quality Council, Quality Enhancement Group. (1996). What are graduates? Clarifying the attributes of graduateness. London: HEQC.

[9] Hu, L., \& Bentler, P. M. (1999). Cutoff criteria for fit indexes in covariance structure analysis: Conventional criteria versus new alternatives. Structural Equation Modelling, 6, 1-55.

[10] Kline, R. B. (2005). Principles and practice of structural equation modeling (2. Edition). New York: The Guilford Press.

[11] Kökdemir, D. (2003). Belirsizlik durumlarında karar verme ve problem çözme, [Decision making and problem solving under uncertainty], Unpublished doctoral dissertation, Ankara Üniversitesi, Sosyal Bilimler Enstitüsü, Ankara.

[12] Norris, S. P. (2003). The meaning of critical thinking test performance: The effects of abilities and dispositions on scores. D. Fasko (Ed.), Critical thinking and reasoning: Current research, theory and practice (pp. 315-329). Cresskill, NJ: Hampton Press.

[13] Paul, R., Elder, L., \& Bartell, T. (1997). California teacher preparation for instruction in critical thinking: Research findings and policy recommendations. Sacramento, CA: Commission on Teacher Credentialing.

[14] Ricketts, J. C., \& Rudd, R. D. (2005). Critical thinking of selected youth leaders: The efficacy of critical thinking dispositions, leadership and academic performance. Journal of Agricultural Education, 46(1), 33-44.

[15] Rosenthal, R., \& Rosnow, R. L. (2008). Essential of behavioral research (3. Edition). NY: Mcgraw-Hill, Inc.

[16] Sümer, N. (2000). Yapısal eşitlik modelleri: Temel kavramlar ve örnek uygulamalar, [Structural equation models: Basic concepts and sample applications]. Türk Psikoloji Yazılarl, $3(6), 49-74$.

[17] Thompson, B. (2004). Exploratory and confirmatory factor analysis: Understanding concepts and applications (1st Edition). Washington: American Psychological Association. 